\title{
PENINGKATAN DAYA DUKUNG TANAH LEMPUNG PADA PERKERASAN JALAN TANAH MENGGUNAKAN DIFA SOIL STABILIZER DAN ABU SEKAM PADI
}

\author{
Robby Zul Anggara ${ }^{1}$, Yusuf Amran ${ }^{2}$, Agus Surandono ${ }^{3}$ \\ Program Studi Teknik Sipil Universitas Muhammadiyah Metro ${ }^{1,2,3}$ \\ E-mail : obbyzul@gmail.com ${ }^{1}$, yusufamran307@gmail.com² ${ }^{2}$, \\ agussurandono@yahoo.co.id ${ }^{3}$,
}

\begin{abstract}
ABSTRAK
Tanah lempung merupakan tanah yang bersifat multi component, terdiri dari tiga fase yaitu padat, cair, dan udara. Bagian yang padat merupakan polyamorphous terdiri dari mineral inorganis dan organis.Mineral-mineral lempung merupakan subtansi-subtansi kristal yang sangat tipis yang pembentukan utamanya berasal dari perubahan kimia pada pembentukan mineral-mineral batuan dasar. Semua mineral lempung sangat tipis kelompok-kelompok partikel kristalnya berukuran10 koloid $(<0,002 \mathrm{~mm})$ dan hanya dapat dilihat dengan menggunakan mikroskop. Tanah yang kurang baik karakteristiknya perlu dilakukan tindakan perbaikan, salah satunya dengan cara stabilisasi tanah sebagai upaya memperbaiki sifat fisik dan sifat mekanis tanah serta meningkatkan nilai CBR tanah. Stabillisasi mekanis atau stabilisasi kimiawi merupakan salah satu upaya yang bisa dilakukang dengan cara menambahkan zatadditive. Pada penelitian ini zat additive yang digunakan yaitu Difa Soil Stabilizer dengan persentase 0,2\%, 0,4\%, 0,6\%, dan 0,8\% sedangkan untuk abu sekam padi menggunakan persentase $8 \%$. Menurut sistem klasifikasi USCS, hasil pengujian sifat fisik tanah asli menunjukkan bahwa tanah tersebut memiliki nilai batas cair (LL) rata-rata sebesar 26\%, dan nilai indeks plastisitas (PI) rata-rata sebesar $4,95 \%$. Apabila nilai tersebut diplotkan pada diagram plastisitas maka tanah tersebut masuk dalam kelompok lempung anorganis dan lempung berpasir dengan plastisitas rendah. Menurut sistem klasifikasi AASTHO, sampel tanah termasuk kedalam kelompok A-2-4. Tanah golongan ini termasuk tipe kerikil dan pasir yang berlanau atau berlempung. Dari pengujian yang telah dilakukan nilai CBR yang didapat dari tanah lempung berpasir menunjukkan nilai sebesar 4,20\% yang mana untuk nilai tersebut belum memenuhi syarat dari Bina Marga yaitu sebesar 6\%. Maka dari itu perlu dilakukan stabilisasi mekanis menggunakan Difa Soil Stabilizer dan abu sekam padi. Pada pengujian ini dapat disimpulkan bahwa penggunaan zat additive berupa Difa Soil Stabilizer dan abu sekam padi dapat meningkatkan daya dukung tanah lempung berpasir untuk akses jalan tanah. Terutama untuk CBR tanah dengan meningkatkan persentase zat additive dan kadar air yang tepat maka akan semakin baik pula nilai CBR yang didapat. Pada penelitian ini didapatkan nilai CBR optimumnya sebesar $7,17 \%$ pada campuran $0,6 \%$ Difa Soil Stabilizer dan $8 \%$ abu sekam padi.
\end{abstract}

Kata Kunci : CBR, Difa Soil Stabilizer, Stabilisasi, Tanah lempung, zat additive

\section{PENDAHULUAN}

Tanah dasar (subgrade) secara umum dapat didefinisikan sebagai lapisan tanah yang letaknya paling bawah atau permukaan tanah semula atau permukaan galian maupun timbunan yang kemudian dipadatkan dan 
diletakkan pada bagian bawah pada suatu konstruksi pekerjaan jalan (Verdy, 2015), bertujuan agar tanah timbunan tidak mengalami longsor.

Penanganan yang dilakukan untuk memperbaiki sifat-sifat tanah lempung yang kurang baik biasanya dilakukan dengan cara stabilisasi tanah dasarnya, yang dimaksud stabilisasi tanah adalah pencampuran tanah dengan bahan tambah (additive) yang sifatnya dapat menguatkan atau memperbaiki sifat-sifat struktur tanah agar memenuhi syarat teknis tertentu. Beberapa bahan campuran yang sudah digunakan sebagai bahan stabilisasi tanah antara lain seperti kapur, protland cement, aspal, geosintetil maupun abu vulkanik.

Adapun sampel yang digunakan pada penelitian ini berasal dari Desa Nunggal Rejo, Kecamatan Punggur, Kabupaten Lampung Tengah, Lampung. Pengujian ini dilakukan di Laboratorium Mekanika Tanah Universitas Muhammadiyah Metro.

Stabilisasi merupakan upaya untuk memperbaiki sifat dan parameter dari tanah asli agar tanah tersebut sesuai atau memenuhi syarat untuk dipergunakan sesuai fungsinya. Penambahan bahan campuran dalam stabilisai tanah telah lama dikembangkan karena dengan stabilisasi dengan cara ini memiliki keunggulan jika dibandingkan dengan mengganti material baru yaitu lebih ekonomis.Sedangkan stabilisasi secara kimiawi dilakukan dengan memperbaiki gaya ikatan secara mikro antara butir tanah dan bahan pembantu.

Pada penelitian ini peneliti menggunakan bahan additive alternatif lainnya yaitu campuran antara Difa Soil Disabilizer yang diharapkan peneliti mampu menstabilisasi tanah lempung terhadap parameter nilai CBR tanah. Penelitian ini menggunakan sampel Difa Soil Disabilizer berasal dari PT. Difa Mahakarya.

\section{TINJAUAN PUSTAKA}

\section{Pengertian Umum Tanah}

Tanah adalah material yang terdiri dari butiran menerial-meniral padat yang tidak terikat secara kimia satu sama lain dan dari bahan-bahan organik yang telah melapuk disertai dengan zat cair dan gas yang mingisi ruang-ruang kosong diantara partikel-partikel padat tersebut (Das, 1988). Selain itu dalam arti lain tanah merupakan akumulasi partikel meneral atau ikatan antar partikelnya, yang terbentuk karena pelapukan dari batuan (Craig, 1991) . Tanah juga didefinisikan sebagai akumulasi partikel mineral yang tidak mempunyai atau lemah ikatan partikelnya, yang terbentuk karena pelapukan dari batuan .

Diantara partikel-partikel tanah terdapat ruang kosong yang disebut poripori yang berisi air dan udara. Ikatan yang lemah antara partikel-partikel tanah disebabkan oleh pengaruh karbonat atau oksida yang tersenyawa diantara partikelpartikel tersebut, atau dapat juga disebabkan oleh adanya material organik bila hasil dari pelapukan tersebut diatas tetap berada pada tempat semula maka bagian ini disebut tanah sisa (residu soil) . Hasil pelapukan terangkut ke tempat lain dan mengedap di beberapa tempat yang berlainan disebut tanah bawah (transportationn soil) . Media pengakutan tanah berupa gravitasi, angin, air dan gletsyer. Pada saat akan berpindah tempat, ukuran dan bentuk partikel-partikel dapat berubah dan berbagi dalam beberapa rentang ukuran.

\section{Klasifikasi Tanah}

Sistem klasifikasi tanah adalah suatu sistem atau cara pengelompokan tanah berdasarkan sifat dan ciri tanah yang sama atau hampir sama, kemudian diberi nama agar mudah dikenal, diingat, dan dibedakan dengan tanah-tanah lainnya. Tujuan klasifikasi tanah adalah untuk menentukan kesesuaian terhadap pemakaian tertentu, serta untuk 
menginformasikan tentang keadaan tanah dari suatu daerah kepada daerah lainnya dalam bentuk berupa data dasar. Klasifikasi bermaksud membagi tanah menjadi beberapa golongan tanah dengan kondisi dan sifat yang serupa diberi simbol nama yang sama.

Terdapat dua sistem klasifikasi yang sering digunakan, yaitu USCS (Unified Soil Classification System) dan AASHTO (American Association of State Highway and Transportation Officials). Sistemsistem ini menggunakan sifat-sifat indeks tanah yang sederhana seperti distribusi ukuran butiran, batas cair dan indeks plastisitas.

\section{Tanah Lempung}

Tanah lempung merupakan tanah yang bersifat multi component, terdiri dari tiga fase yaitu padat, cair, dan udara. Bagian yang padat merupakan polyamorphous terdiri dari mineral inorganis dan organis. Mineral-mineral lempung merupakan subtansi-subtansi kristal yang sangat tipis yang pembentukan utamanya berasal dari perubahan kimia pada pembentukan mineral-mineral batuan dasar. Semua mineral lempung sangat tipis kelompokkelompok partikel kristalnya berukuran 10 koloid $(<0,002 \mathrm{~mm})$ dan hanya dapat dilihat dengan menggunakan mikroskop.

Tanah lempung merupakan partikel mineral yang berukuran lebih kecil dari $0,002 \mathrm{~mm}$. Partikel-partikel ini merupakan sumber utama dari kohesi di dalam tanah yang kohesif (Bowles, 1991). Menurut Soekoto (1984, dalam Fathani, 1998) menerangkan bahwa "lempung merupakan pertikel-partikel berukuran mikroskopik sampai sub mikroskopik yang berasal dari pelapukan batuan".

Kebanyakan jenis tanah terdiri dari banyak campuran atau lebih dari satu macam ukuran partikel. Tanah lempung belum tentu terdiri dari partikel lempung saja, akan tetapi bercampur butir-butiran ukuran lanau maupun pasir dan mungkin juga terdapat campuran bahan organik. Lempung bersifat kedap air sehingga hampir sepenuhnya terjebak dalam pori-porinya. Sifat plastis dari suatu tanah adalah disebabkan oleh air yang terserap di sekeliling permukaan partikel lempung, maka dapat diharapkan bahwa tipe dan jumlah mineral lempung yang dikandung didalam suatu tanah akan mempengaruhi batas plastis dan batas cair tanah yang bersangkutan. Sifat-sifat yang dimiliki tanah lempung (Hardiyatmo, 2010) adalah sebagai berikut :

a. Ukuran butir halus, kurang dari $0,005 \mathrm{~mm}$,

b. Permeabilitas rendah,

c. Kenaikan air kapiler tinggi,

d. Bersifat sangat kohesif,

e. Kadar kembang susut yang tinggi, dan

f. Proses konsolidasi lambat.

\section{Stabilisasi Tanah}

Stabilisasi tanah adalah usaha untuk merubah atau memperbaiki sifat-sifat teknis tanah dengan menambahkan sesuatu pada tanah tersebut, agar dapat menaikkan kekuatan tanah dan mempertahankan kekuatan geser. Adapun tujuan stabilisasi tanah adalah untuk mengikat dan menyatukan agregat material yang ada sehingga sifat teknis tanah menjadi lebih baik. Sifat-sifat tanah yang dapat diperbaiki dengan cara stabilisasi dapat meliputi : kestabilan volume, kekuatan atau daya dukung, permeabilitas, dan kekekalan atau keawetan.

Menurut Bowles, 1991 beberapa tindakan yang dilakukan untuk menstabilisasikan tanah adalah sebagai berikut :

a. Meningkatkan kerapatan tanah.

b. Menambah material yang tidak aktif sehingga meningkatkan kohesi dan/atau tahanan gesek yang timbul.

c. Menambah bahan yang menyebabkan perubahan kimiawi dan fisis tanah. 
d. Menurunkan muka air tanah (drainase tanah).

e. Mengganti tanah yang buruk.

\section{Tipe-Tipe Stabilisasi}

Pada umumnya tipe atau cara yang digunakan untuk stabilisasi tanah dapat dibagi menjadi tiga yaitu :

a. Stabilisasi Alami

Stabilisasi alami merupakan jenis stabilisasi yang terjadi karena proses alam sehingga tidak membutuhkan perlakuan khusus dalam memperbaiki sifat mekanis tanah. Contoh tanah memadat akibat berat sendiri, resapan air hujan, penyusutan air akibat penguapan, akar tanaman dan lainlain.

b. Stabilisasi Mekanis

Stabilisasi mekanis atau mekanikal dilakukan dengan cara mencampur atau mengaduk dua macam tanah yang bergradasi berbeda secara proporsional yang diikuti dengan proses pemadatan, untuk mendapatkan kepadatan maksimum. Stabilisasi mekanis juga dapat dilakukan dengan cara menggali tanah buruk ditempat dan menggantinya dengan material granular dari tempat lain. Menurut Lambe (1962) stabilisasi mekanis merupakan suatu proses yang menyangkut dua cara perubahan sifatsifat tanah :

1. Penyusunan kembali partikel tanah, seperti contohnya pencampuran beberapa lapisan tanah, pembentukan kembali tanah yang telah terganggu dan pemadatan.

2. Penambahan atau penyingkiran partikel tanah. Contohnya lempung berpasir dicampur dengan kerikil untuk memenuhi daya dukung di jalan tertentu.

c. Stabilisasi Kimiawi

Stabilisasi dengan bahan tambah atau dapat disebut juga stabilisasi kimiawi yaitu stabilisasi menggunakan bahan kimia untuk memungkinkan terjadinya reaksi kimia, dan menghasilkan senyawa baru yang bersifat stabil. bertujuan untuk memperbaiki sifat-sifat teknis tanah. Metode ini dapat menggunakan larutan kimia/bubuk kimia, yang dicampurkan dengan tanah yang akan diperbaiki, dengan beberapa metode pencampuran yang disesuaikan dengan kondisi bahan pencampur maupun kondisi tanahnya. Contoh Kapur, semen portland, abu terbang (fly ash) aspal dan lain-lain.

\section{Difa Soil Stabilizer}

Difa soil stabilizer adalah bahan additive yang berfungsi untuk memadatkan (solidifikasi) dan menstabilkan (stabilizer) tanah secara fisik-kimia yang berupa material serbuk halus yang terdiri dari komposisi mineral anorganik. Stabilisasi dengan menggunkan bahan tambahan atau sering disebut juga stabilisasi kimiawi bertujuan untuk memperbaiki sifat-sifat teknis tanah, dengan cara mencampur tanah dengan penggunanan bahan tambahan dengan komposisi perbandingan yang sudah ditetapkan. Jika percampuran hanya dimaksudkan hanya untuk mengubah gradasi dan plasitas tanah, dan kemudian dikerjakan, maka hanya diperlukan penambahan zat additive yang sedikit. Namun stabilisasi dimaksudkan untuk merubah tanah agar mempunyai kekuatan tinggi, maka diperlukan bahan pencampuran zat additive ini harus dihampar dan disimpan ditempat yang baik supaya mendapat nilai yang diinginkan .

Difa soil stabilizer adalah salah satu stabisasi kimiawi dengan cara ion exchange, produk ini dikembangkan PT. DIFA MAHA KARYA yang beralamatkan Jl. Kaliurang KM.13, RT 04/RW 09, No.120, Dusun Wonosalam, Desa Sukaharjo, Ngagli Sleman 55581, Yogyakarta . 
Soil stabilizer adalah metode perbaikan tanah untuk dapat memenuhi spesifikasi teknis material dalam aplikasi teknik stbalisasi tanah dapat dilakuakan secara mekanis dan kimiawi. Stabilisasi secara mekanis adalah dengan memperbaiki sifat tanah secara fisik, biasanya dilakukan dengan mengurangi volume rongga udara pada kadar air yang optimum saat pemadatan (compoction) dilakuakan. Sedangkan stabilisasi secara kimiawi dilakuakan dengan memperbaiki gaya ikatan secara mikro antara butir tanah dan bahan pembantu yaitu difa soil stabilizer.

\section{Abu Sekam Padi}

Abu sekam padi merupakan sisa pembakaran dari sekam padi, sehingga pada prinsipnya abu sekam padi ini merupakan limbah sisa pembakaran. Namun berdasarkan penelitianpenelitian yang telah lalu menunjukkan bahwa abu sekam padi memiliki kandungan kimia yang dapat dimanfaatkan untuk stabilisasi tanah karena sifat pozolan dari bahan kimia tersebut. Hasil analisis lebih lanjut pada abu sekam padi menunjukkan bahwa kandungan $\mathrm{SiO} 2$ mencapai 80 - 90\%, yang memiliki sifat perekat, sehingga pemanfaatannya sudah banyak digunakan yakni dengan mereaksikannya dengan larutan $\mathrm{NaOH}$ untuk menghasilkan natrium silikat sehingga dalam industry dapat dimanfaatkan sebagai bahan filler dalam pembuatan sabun dan detergen, bahan perekat (adhesive), dan jeli silika (silica gel) (Wanadri, 1999, dalam Abdurrozak \& Azzanna, 2017).

Widhiarto dkk (2015) menyatakan bahwa abu sekam padi banyak mengandung silika dan material pozzolan karena mengandung unsur kapur bebas yang dapat mengeras dengan sendirinya, disamping mengandung unsur alumunium dioksides yang keduanya merupakan unsur-unsur yang mudah bereaksi dengan kapur.
Menurut Balai Besar Institut Kimia (1982, dalam Widhiarto dkk., 2015), unsur-unsur kimia yang terkandung pada abu sekam padi disajikan pada Tabel berikut ini.

Tabel 1. Unsur-Unsur yang Terkandung dalam Abu Sekam Padi

\begin{tabular}{ccc}
\hline No. & Unsur & Kandugan (\%) \\
\hline 1. & $\mathrm{SiO}_{2}$ & 21,6 \\
2. & $\mathrm{Al}_{2} \mathrm{O}_{3}$ & 4,6 \\
3. & $\mathrm{Fe}_{2} \mathrm{O}_{3}$ & 2,8 \\
4. & $\mathrm{CaO}$ & 62,8 \\
5. & $\mathrm{MgO}$ & 3,2 \\
6. & $\mathrm{So}_{4}$ & 2,1 \\
7. & $\mathrm{CaO}$ bebas & 0,41 \\
8. & $\mathrm{Na}_{2} \mathrm{O}$ & 0,41 \\
9. & $\mathrm{~K}_{2} \mathrm{O}$ & 0,24 \\
\hline
\end{tabular}

(Balai Besar Institut Kimia,1982, dalam Widhiarto dkk., 2015)

\section{Pengujian Sifat Mekanis Tanah}

Stabilisasi mekanis atau stabilisasi mekanikal dilakukan dengan mencampur atau mengaduk dua macam tanah atau lebih yang bergradasi berbeda untuk memperoleh material yang memenuhi syarat yang telah ditentukan komposisi tambahannya. Pencampuran tanah ini dapat dilakukan dilokasi proyek atau di laboratorium, dipabrik, atau dilakukan di tempat pengambilan bahan timbunan (borrow area) tetapi penelitian ini dilakukan di labratorium Teknik Sipil Universitas Muhammadiyah Metro, Lampung. Material yang telah dicampur ini, kemudian dihamparkan dan dipadatkan di laboratorium. Stabilisasi mekanis juga dapat dilakukan dengan cara mengambil tanah langsung ditempat dan menggantinya dengan material granuler ditempat lain .

Menurut lambe (1962), dan Hary Cristady Hardiyatmo (2010), stabilisasi mekanis merupakan suatu proses yang menyangkut dua cara perubahan sifat sifat tanah :

a. Penyusunan kembali partikel partikel tanah, seperti contohnya pencampuran beberapa lapisan tanah, pembentukan kembali tanah yang telah terganggu dan pemadatan . 
b. Penambahan atau penyingkiran partikel-partikel tanah, sifat fisik tanah tertentu dapat diubah dengan menambahkan dan memisahkan ini umumnya sangat lebih rendah dibandingkan dengan metode stabilisasi yang lain .

\section{METODE PENELITIAN}

\section{Teknik Sampling}

Sampel tanah lempung yang diambil berada di Desa Nunggal Rejo, Kecamatan Punggur, Kabupaten Lampung Tengah, Lampung. Pengujian sampel tanah dibagi menjadi dua yaitu pengujian sifat fisik tanah dan pengujian sifat mekanis tanah, yang meliputi;
a. Pengujian Sifat Fisik Tanah
1) Kadar Air
2) Berat Jenis
3) Analisa Saringan
4) Atterberg Limit
b. Pengujian Sifat Mekanis Tanah
1) Uji Proctor
2) Uji CBR

\section{Tahapan}

Setelah mendapatkan sampel yang akan digunakan untuk penelitian selanjutnya dilakukan pengukuran di laboratorium untuk mengukur kadar air, berat jenis, analisa saingan, atterberg limit, uji proctor, dan uji CBR.

\section{Teknik Pengumpulan Data}

Data-data yang dijadikan sebagai bahan acuan dalam pelaksanaan dan penyusunan laporan penelitian ini dikelompokkan dalam dua jenis data, yaitu; data primer dan data sekunder.

\section{Data Primer}

Data primer adalah data yang diperoleh dari lokasi bangunan maupun hasil survei yang dapat langsung dipergunakan sebagai sumber. Pengamatan langsung di lapangan mencakup kondisi tanah yang ada di lapangan.

2. Data Sekunder
Data sekunder merupakan data yang dipakai dalam pelaksanaan penelitian ini. Data sekunder ini didapatkan bukan melalui pengamatan secara langsung di lapangan. Yang termasuk dalam klasifikasi data sekunder ini antara lain adalah literatur-literatur penunjang, grafik, tabel yang berkaitan dengan Stabilitas Tanah Lempung Dengan Penambahan Zat Additive Berupa Difa Soil Disabilizer dan Abu Sekam Padi Untuk Perkerasan Akses Jalan Tanah.

\section{Instrumen Penelitian}

Pelaksanaan pengujian dilakukan di Laboratorium Mekanika Tanah Teknik Sipil, Universitas Muhammadiyah Metro, Lampung. Pengujian yang dilakukan dibagi menjadi 2 bagian pengujian yaitu pengujian untuk tanah asli dan tanah yang telah distabilisasi, adapun pengujian-pengujian tersebut adalah sebagai berikut:

1. PengujianSampel Tanah Asli

a. PengujianAnalisa Saringan

b. PengujianBerat Jenis

c. Pengujian Kadar Air

d. Pengujian Batas Atteberg Limit

e. Pengujian Pemadatan Tanah (proctor)

f. Pengujian CBR

2. Pengujian pada tanah lempung yang telah distabilisasi dengan Difa dan abu sekam padi.

a. Pengujian Pemadatan Tanah (proctor)

b. Pengujian CBR

\section{Teknik Analisis Data}

Analisis dan pengolahan data dilaksanakan berdasarkan data-data yang diperlukan untuk selanjutnya dikelompokkan sesuai identifikasi permasalahan. Semua hasil yang didapat dari pengujian-pengujian yang dilaksanakan dilapangan dan di laboratorium akan ditampilkan dalam bentuk tabel, grafik. 


\section{HASIL PENELITIAN}

\section{Pengujian Sifat Fisik Tanah}

Berikut ini adalah rekapitulasi hasil pengujian sifat fisik tanah asli yang berasal dari Desa Nunggal Rejo, Kecamatan Punggur, Kabupaten Lampung Tengah, Lampung.

Tabel 2. Rekapitulasi Hasil Pengujian Sifat Fisik Tanah

\begin{tabular}{clcc}
\hline No. & \multicolumn{1}{c}{ Pengujian } & Satuan & Hasil \\
\hline 1. & Kadar Air (w) & $\%$ & 20,11 \\
2. & $\begin{array}{l}\text { Analisa Saringan } \\
\text { Lolos Saringan No. 200 }\end{array}$ & $\%$ & 1,83 \\
& $\begin{array}{l}\text { Atterberg Limit } \\
\text { Batas Cair (LL) }\end{array}$ & $\%$ & 26 \\
3. & $\begin{array}{l}\text { Batas Plastis (PL) } \\
\text { Indeks Plastisitas (PI) }\end{array}$ & $\%$ & 21,05 \\
4. & $\begin{array}{l}\text { Berat Jenis (Gs) } \\
\text { Pemadatan (Modified) }\end{array}$ & $\mathrm{Gr} / \mathrm{cm}^{3}$ & 2,49 \\
5adar Air Optimum & $\%$ & 7 \\
(OMC) & $\begin{array}{l}\text { Berat Isi Kering } \\
\text { Maksimum ( } \gamma_{\text {max }} \text { ) }\end{array}$ & $\mathrm{Gr} / \mathrm{cm}^{3}$ & 1,74 \\
6alifirnia Bearing Ratio & $\%$ & 4,20 \\
\hline
\end{tabular}

(Hasil Pengujian Di Laboratorium, 2020)

Menurut sistem klasifikasi USCS, hasil pengujian sifat fisik tanah asli menunjukkan bahwa tanah tersebut memiliki nilai batas cair (LL) rata-rata sebesar $26 \%$, dan nilai indeks plastisitas (PI) rata-rata sebesar 4,95\%. Apabila nilai tersebut diplotkan pada diagram plastisitas maka tanah tersebut masuk dalam kelompok lempung anorganis dan lempung berpasir dengan plastisitas rendah.

Menurut sistem klasifikasi AASTHO, persentase lolos saringan No. 200 adalah1,83\% ( $\leq 35 \%)$ secara umum tanah tersebut termasuk kelompok tanah berbutir. Hasil pengujian batas cair (LL) adalah $26 \% \quad(\leq 40 \%)$, nilai indeks plastisitas (PI) adalah 4,95\% ( $\leq 10 \%)$, maka sampel tanah termasuk kedalam kelompok A-2-4. Tanah golongan ini termasuk tipe kerikil dan pasir yang berlanau atau berlempung.
Pengujian Sifat Mekanis Tanah

Tabel 3. Rekapitulasi Hasil

Pengujian Pemadatan Tanah Asli + Difa

SoilStabilizer + Abu Sekam Padi.

\begin{tabular}{|c|c|c|c|c|c|}
\hline \multirow[b]{2}{*}{ No. } & \multicolumn{2}{|c|}{ Campuran } & \multirow{2}{*}{\multicolumn{2}{|c|}{$\begin{array}{c}\text { Kadar Air } \\
\text { Optimum } \\
(\%)\end{array}$}} & \multirow[b]{2}{*}{$\begin{array}{c}\text { Berat } \\
\text { Kering } \\
\text { Maksimum } \\
\left(\mathrm{gr} / \mathrm{cm}^{3}\right)\end{array}$} \\
\hline & $\begin{array}{c}\text { Difa } \\
\text { SS } \\
(\%)\end{array}$ & $\begin{array}{c}\text { Abu } \\
\text { Sekam } \\
\text { Padi } \\
(\%)\end{array}$ & & & \\
\hline 1. & 0 & 0 & \multicolumn{2}{|c|}{7} & 1,74 \\
\hline 2. & 0,2 & 8 & \multicolumn{2}{|c|}{12,50} & 1,89 \\
\hline 3. & 0,4 & 8 & \multicolumn{2}{|c|}{8,60} & 1,65 \\
\hline 4. & 0,6 & 8 & \multicolumn{2}{|c|}{15,25} & 1,65 \\
\hline 5. & $\mathbf{0 , 8}$ & 8 & \multicolumn{2}{|c|}{17,60} & 2,05 \\
\hline \multicolumn{6}{|c|}{$\begin{array}{l}\text { Pengujian CBR Campuran Tanah Asli + } \\
\text { Abu SekamPadi }\end{array}$} \\
\hline No & $\begin{array}{c}\text { Kadar } \\
\text { Campu } \\
\text { ran } \\
\text { Difa } \\
\text { Soil } \\
\text { Stabiliz } \\
\text { er }(\%)\end{array}$ & $\begin{array}{c}\text { Kadar } \\
\text { Campu } \\
\text { ran } \\
\text { Abu } \\
\text { Sekam } \\
\text { Padi } \\
(\%) \\
\end{array}$ & $\begin{array}{l}\text { Nilai } \\
\text { CBR } \\
\text { Pada } \\
0,1 \% \\
(\%)\end{array}$ & $\begin{array}{c}\text { Syarat } \\
\text { Menuru } \\
\text { t Bina } \\
\text { Marga } \\
(\%)\end{array}$ & $\begin{array}{c}\text { Keteranga } \\
\text { n }\end{array}$ \\
\hline 1. & 0 & 8 & 4,20 & 6 & $\begin{array}{l}\text { Tidak } \\
\text { Memenuhi } \\
\text { Syarat }\end{array}$ \\
\hline 2. & 0,2 & 8 & 5,13 & 6 & $\begin{array}{l}\text { Tidak } \\
\text { Memenuhi } \\
\text { Syarat }\end{array}$ \\
\hline 3. & 0,4 & 8 & 6,80 & 6 & $\begin{array}{c}\text { Memenuhi } \\
\text { Syarat }\end{array}$ \\
\hline 4. & 0,6 & 8 & 7,17 & 6 & $\begin{array}{c}\text { Memenuhi } \\
\text { Syarat }\end{array}$ \\
\hline 5. & 0,8 & 8 & 6,47 & 6 & $\begin{array}{c}\text { Memenuhi } \\
\text { Syarat }\end{array}$ \\
\hline
\end{tabular}

(Hasil Pengujian Di Laboratorium, 2020)

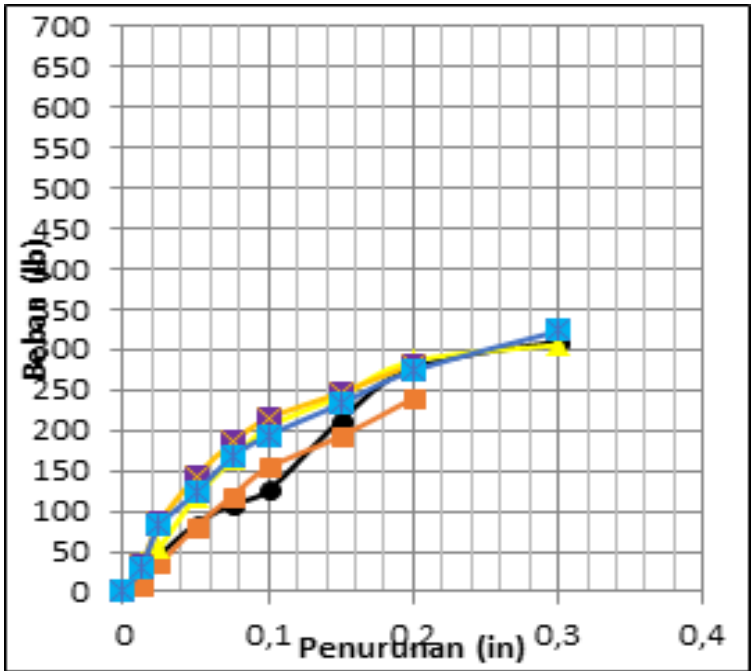

Gambar 1. Grafik Rekapitulasi Pengujian CBR Tanah Asli + Difa Soil Stabilizer +Abu Sekam Padi. 
(Sumber: Robby Zul Anggara, 2020)

Keterangan:

$\ominus$ Tanah Asli

Tanah Asli + Difa Soil Stabilizer

$(0,2 \%)+$ Abu Sekam Padi (8\%)

Tanah Asli + Difa Soil Stabilizer

$(0,4 \%)+$ Abu Sekam Padi $(8 \%)$

- Tanah Asli + Difa Soil Stabilizer $(0,6 \%)+$ Abu Sekam Padi $(8 \%)$

Tanah Asli + Difa Soil Stabilizer $(0,8 \%)+$ Abu Sekam Padi $(8 \%)$

Dari hasil pengujian CBR tanah campuran jika dibandingkan dengan hasil pengujian CBR tanah asli nilai yang diperoleh mengalami kenaikan atau peningkatan dari mulai campuran Difa Soil Stabilizer sebanyak 0,2\%, 0,4\%, $0,6 \%$. Sedangkan pada campuran $0,8 \%$ terjadi penurunan nilai CBR yang dipengaruhi oleh kadar air yang kurang optimum.

Dari hasil pengujian yang telah dilakukan dengan penambahan campuran zat additive berupa Difa Soli Stabilizer dan abu sekam padi dengan persentase yang telah ditentukan didapatkan nilai CBR yang sesuai dengan syarat minimum yaitu $6 \%$ diperoleh pada campuran Difa SoilStabilizer sebanyak 0,4\% Difa Soil Stabilizer dan 8\% abu sekam padi yang menghasilkan nilai CBR sebesar 6,80\%.

Pada penelitian yang telah dilakukan di laboratoium bertujuan untuk mendapatkan hasil dari parameter sifat fisik dan sifat mekanis tanah yang telah distabilisasi mengunakan Difa Soil Stabilizer dan abu sekam padi berupa nilai ${ }^{\gamma} d_{\max }$, OMC dan CBR Laboratorium. Nilai CBR yang disyaratkan oleh Bina Marrga yaitu sebesar 6\%, hal menunjukkan persentase kadar campuran 0,6\% Difa Soil Stabilizer dan 8\% abu sekam padi sudah sesuai dengan yang disyaratkan untuk tanah dasar, yang mana pada campuran tersebut menghasilkan nilai CBR sebesar 7,17\%.

\section{KESIMPULAN}

Dari hasil pengujian pemadatan tanah asli yang telah dilakukan didapatkan kadar air optimumnya (OMC) sebesar $7 \%$ dan berat isi keringnya $\left(\gamma d_{\max }\right)$ sebesar $1,74 \mathrm{gr} / \mathrm{cm}^{3}$. Setelah ditambahkan zat additive berupa Difa Soil Stabilizer dan abu sekam padi kadar air optimum dan berat isi keringnya semakin meningkat, terutama pada campuran difa sebanyak $0,8 \%$ dan abu sekam padi $8 \%$ yang didapatkan nilai kadar air optimumnya $17,60 \%$ dan berat isi keringnya 2,05 $\mathrm{gr} / \mathrm{cm}^{3}$. Sedangkan untuk nilai CBR yang didapat dari tanah lempung berpasir menunjukkan nilai sebesar 4,20\% yang mana untuk nilai tersebut belum memenuhi syarat dari Bina Marga yaitu sebesar 6\%. Maka dari itu perlu dilakukan stabilisasi mekanis menggunakan Difa Soil Stabilizer dan abu sekam padi. Pada pengujian ini dapat disimpulkan bahwa penggunaan zat additive berupa Difa Soil Stabilizer dan abu sekam padi dapat meningkatkan daya dukung tanah lempung berpasir untuk akses jalan tanah. Terutama untuk CBR tanah dengan meningkatkan persentase zat additive dan kadar air yang tepat maka akan semakin baik pula nilai CBR yang didapat. Pada penelitian ini didapatkan nilai CBR optimumnya sebesar $7,17 \%$ pada campuran $0,6 \%$ Difa Soil Stabilizer dan $8 \%$ abu sekam padi, yang mana nilai tersebut sudah memenuhi syarat dari Bina Marga.

\section{DAFTAR PUSTAKA}

Abdurrozak M. Rifqi, Mufti N. Dillah. 2017. Stabilisasi Tanah Lempung Dengan Bahan Tambah Abu Sekam Padi dan Kapur Pada Subgrade Perkerasan Jalan. Jurnal Tekniksa, 22(2), h. 416-424

Adha Idharmahardi. 2011. Pemanfaatan Abu Sekam Padi Sebagai Pengganti Semen Pada Metoda 
Stabilisasi Tanah Semen. Jurnal Rekayasa, 15(1),h. 33-40

Amran Yusuf, Sari D. Utama. 2018. Analisa Perbaikan Sub Grade/Tanah Dasar Menggunakan Bahan Tambahan Kapur Dan Abu Sekam Padi Pada Ruas Jalan Ki Hajar Dewantara, 38 BBanjar Rejo Lampung Timur-Batas Kota Metro. Tapak (Teknologi Aplikasi Kontruksi), 8(1), h. 18.

Amran Yusuf, Sadiya Rizqi. 2019. Analisis Peningkatan Sifat Mekanis Tanah Dasar Menggunakan Campuran Abu Limbah Ampas Tebu dan Semen.Tapak (Teknologi Aplikasi Kontruksi), 9(1), h. 7483.

Ariyani Ninik, Nugroho A.C. 2007. Pengaruh Kapur dan Abu Sekam Padi Pada Nilai CBR Laboratorium Tanah Tras Dari Dusun Seropan Untuk Stabilitas Subgrade Timbunan. Majalah Ilmiah UKRIM, 12(1), h. 1-16

Badan Standarisasi Nasional. 2015. Tata Cara Pengklasifikasian Tanah Untuk Keperluan Teknik Dengan Sistem Klasifikasi Unifikasi Tanah. Jakarta.

Hardiyanto H. Christady. 2010. Stabilisasi Tanah Untuk Perkerasan Jalan.Gadjah Mada Unuversity Press. Yogyakarta.

Kurniawan, S., Hadijah, I., \& Rizqi, D.

A. (2020). Analisis Daya Dukung Tanah Dan Beban Kendaraan Terhadap Kerusakan Perkerasan Jalan Pada Ruas Jalan Raya Metro-Tanjungkari. TAPAK (Teknologi Aplikasi Konstruksi): Jurnal Program Studi Teknik Sipil, 9(2), 159168.

PT. DifaMahakarya. Profile Product. Yogyakarta.
Raswitaningrum T. Rahayu, Juliatna. 2017, Penambahan Semen dan Abu Sekam Padi Untuk Peningkatan Stabilitas Tanah. Semnastek, h. 1-10 Surendro Bambang. 2015.

Mekanika Tanah. C.V. Andi Offset. Yogyakarta.

Saodang Hamirhan. 2004. Perancangan Perkerasan Jalan. Nova. Bandung.

Zaenuri Moch, Romadhon. 2019. Stabilisasi Tanah Lendut Mengggunakan Penambahan Abu Kayu Bakar Dan Semen Portland Tipe 1, 4(2), h. 268275. 